Public Philosophy \& Democratic Education

Volume 5 • 2016 • Issue 2 • pp. 133-156 • DOI: 10.14746/fped.2016.5.2.21

Participatory Methods for Information Society Www. filozofiapubliczna.amu.edu.pl • ISSN 2299-1875

@) (reative Commons BY-NC-ND 4.0

\title{
Homo Sapiens, Homo Faber and Homo Dictyous. Creatively united by computing science
}

\section{Cätölíin Mamali}

Abstruct: The present essay is a reflection inspired by the excellent book "Human Face of Computing" (editor Cristian S. Calude, published by Imperial College, Press, 2016) that is the outcome of a participatory exploration carried out by and insider (C. Calude) on the history of computing science with with its wide and deep ramification that are influencing all human activities. The book is based on interviews with outstanding researchers in computing science, mathematics, Internet, physics and technological sciences who have landmark contributions to computing science and are deeply interested in its applications, impact, uses and abuses in social life. The book explores the consequences of this field on the quality, production and democratization of knowledge.

Keywords: computing science, common-sense knowledge, monopoly, natural computing, Internet, behavior programming, new intelligibilities, invalidation, data complexity, query complexity

The Human Face of Computing (editor Cristian S. Calude, published by Imperial College Press, London, 2016) offers questions, puzzles, solutions and narratives of landmark scientific journeys within a field that significantly penetrated all other human fields of inquiry and practice, including

\footnotetext{
* Department of Social Sciences, Northeast lowa Community College (USA) catalin.mamali@loras.edu
} 
psychology. This is computing science. The book achieves an excellent participatory exploration of the mode in which eminent insiders look to the dynamics of the field, to their own crucial contributions and to the societal and global challenges. This collaborative introspection is achieved through conversational interviews initiated by an insider of the field (Calude). The creative researchers are deeply interested, willing and able to look to computing not only from within but also from the perspectives of its interaction with many other areas while it is rapidly developing. The scientists take various perspectives based on their rich experiences of solving major theoretical and practical problems. The conversational interviews of insiders opened to the interactions of their work with the world complement significantly through their content and participative nature a rich literature dedicated to the evolution of science (Boltzmann, 1974; Feyerabend, 1979; Holton, 1973; Knorr-Cetina, 1981; Kuhn, 1962; Latour \& Woolgar, 1986; Merton, 1973; Mitroff, 1974; Pólya, 2004; Popper, 1959).

Computing science, as an inter- and transdisciplinary science with its major roots in mathematics, logics, physics, informatics and engineering, which, all have been influenced by its dynamics, is since a few decades more and more intertwined with biology, economy (finance), neuroscience, astrophysics, social sciences, military power, politics and with major concerns about the state of our world such as understanding, democracy, safety, interconnectivity, human rights and future.

The book includes 26 interviews organized in three parts: 1. Computing science; 2. Computing in biology, mathematics and physics; 3. Social aspects of computing, plus a Foreword by Anil Nerode and a Postface by the editor. The structure of the book enhances the value of the thematic interconnections among its dialogical-interviews.

Theoretical research, and of course its transdisciplinary and applicative sides, represents one of the major themes. Many psychologists who read and/or heard many times Lewin's statement "There is nothing so practical as a good theory" may find out that this idea has been expressed some 50 years before within a scientific field that influenced Lewin's thinking: physics. Dines Bjørner mentions 
Ludwig E. Boltzmann's idea: "There is nothing so practical, that is of use in engineering, as a good theory" (p. 7). The value of theory for the development of applications, many unpredictable at the dawn of a theory, emerges unexpectedly in time. For instance, this seems to be the case with the theoretical studies on "discreteness" that complement the interest of classical mathematics on "continuity". Theoretical research on "formal specification" and "verification" is considered to be a "cornerstone of today's software engineering" (p. 7). Dines Bjørner who worked on Vienna Development Method (VDM) of IBM considers that such theoretically grounded methods should be developed more in an open, peer reviewed environment than within a competition and profit oriented one (p. 9). In some highly complex areas, such as Internet, the relation theory-practice is fluid and one should consider, at least for safety reasons of "scaling, stability, and security", both a "realistic theory" and a "theoretical theory" as Brian Carpenter argues (p. 358).

The vital role of theory is supported by the epistemic longevity and practical use of fundamental research. For instance, the "mathematical definition of the general notion (concept!) of algorithm" carried out by Church, Kleene, Turing (Nerode, p. X), or the crucial importance of Gödel's incompleteness theorems (Longo, pp. 261-262). Theoretical foundations advance knowledge within specialized areas of inquiry as well as in interdisciplinary areas (mathematics-physics-biology, for instance) and are a must for the innovative reproduction and development of scientific potential through education (Longo, p. 259). Theoretical developments and applications of solutions to foundational problems are essential ways through which new powerful ideas enter the field. For instance, this is the case with the issue of "how computational complexity of problems changed with changes to the Turing machine model" and if one can quantify the changes as it has been proved by research of Juris Hartmanis (p. 51). Such theoretical issues require a deep and accurate knowledge of the "history of theoretical computer science" in close connection with the much older history of mathematics and its classical fields as Solomon Marcus argued (p. 301). The theoretical challenges imply the drive and ability of "inventing new principles of theoretical 
construction" thus opening new directions that "propose new intelligibilities", as Giuseppe Longo posits (p. 257), and among other elements, they imply a fertile interaction between theory and applications as Erol Gelenbe suggests based on his own experience: "much of my work has had a theoretical bent, but it has almost been driven by a strong link between engineering requirements or by observations from nature" (p. 16).

The dialogical-interviews carried out from inside the field being at the same time complemented by taking the perspective of many other human fields, which are benefiting from and enriching the computing science, help the reader to better grasp questions regarding the dynamics and unpredictability of the interdependence between theoretical innovations and applications. David Harel reveals that the reawakening of the need for theory might be triggered by useful activities, which, sometimes might look as being unchallenging. He recalls: "I said to myself: 'OK, great, I can now write a program that computes the average of a series of numbers what else is there to learn in computer science?" (p. 36). There is evidence that the ability of self-inquiry facilitates crucial cognitive, emotional and relational changes. His supervisor, Amir Pnueli, asked him to study Mathematical Theory of Computation by Zohar Manna, a reading that turned into a crucial cognitive experience. After working as consultant for Israel Aircraft Industries, he identified, together with Pnueli, the "reactive systems" (p. 39) and later on developed the area of behavior programing, which refers to the "most general notion of programing; to cause other entities to do what we have in mind for them" (p. 43). This notion invites itself to further basic conceptual explorations regarding its cognitive (inclusive computing), ethical and political assumptions and consequences. Theory, as an essential source of understanding, helps to generate valid algorithms and at the same time is not limited by them as Gregory Chaitin states: "I don't believe in absolute truth, in total certainty... I think that incompleteness means that we have to also accept heuristic proofs, the kinds of proofs that George Pólya liked" (p. 178). The inquiring power of computing science is enhanced by a constructive criticism of the limits of human activities, be it even 
mathematics. Mosher Vardi, a co-winner of Gödel Prize, said: "Gödel's Incompleteness theorems established limits on the power of the mathematical approach. It showed that mathematics is a human activity (or, as sociologists would say a 'social construct', i.e., Berger and Luckmann) with all the limitations that are implied by that" (p. 411). This view expressed in different ways by Chaitin and Vardi are shared by many outstanding researchers of this field and resonates with Boltzmann's view: "no theory can be objective, actually coinciding with nature, but rather that each theory is only a mental picture of phenomena, related to them as sign is to designatum. From this it follows that it cannot be our task to find an absolutely correct theory, but rather a picture that is as simple as possible and that represents phenomena as accurately as possible" (Boltzmann, 1974). Theories are so practical not just because of their intrinsic features and their accurate representation of reality but also because they invite the construction of other theories about the same reality, they invite alternative explanations. The theory intertwined with observation, experiments and applications needs and feeds all the possible ways of valid verifications, which include self-verifications, inter-subjective verifications, computer enhanced verifications, applications, which are aiming to be as close as possible to "objective" verifications.

The creativity of theoretical research is revealed both by its new ideas as well as by its ability to cope with the new problems posed by applications, i.e., by failures. Kurt Mehlhorn who, together with Stefan Näher, started the $L E D A$ project (Library of Efficient Data Types and Algorithms, pp. 65-66) faced such problems, some of them rooted even in the work of a former student, and developed ways of "formal verifications" by answering to the question "who validates the work of the checker?" (p. 67). This is also a great pedagogical example regarding the cooperation between mentor and mentee as well as concerning the creatively assumed responsibility of the mentor. The verification capacity is closely related with a core goal of computer science, which according to Joseph Sifakis, a researcher with recognized contributions in "modeling and analysis of real-time system with focus on correct by construction techniques" 
(p. 87), with the complex requirements of using computer science for building artifacts: "The key issue is constructivity, that is, the ability to effectively build correct systems" with the explicit aim of avoiding "a posteriori verification as much as possible" (p. 100). Sifakis pleads for the balanced use of two complementary functions of inquiry: (a) understanding function (predicting the world); (b) prescriptive function, i.e., "applying a theory in order to assess its explicability and predictability, as well as to invent things that do not yet exist" (p. 102). The sources of innovative theories are very diverse. Some of them are related to an attraction toward "themata", which are at the core of "scientific imagination" (Holton) and might emerge in childhood. For instance, the theoretical computing scientist Arto Salomaa who has crucial contributions in formal languages and theory of automata recalls: "as a small boy I used to think of questions such as the dependence of the parity of the sum on the parties of the summands (Of course I did not use these terms)" (p. 75).

Theory construction, sometimes, is located at the intersections among various inquiring fields and it, usually, requires high levels of formalization. Mioara Mugur-Schachter developed the method of relativised conceptualization that "concerns all of the human processes of conceptualization: it is a general syntax for normalized creation of consensual knowledge" (p. 319). With her background in logic and psychology and a master in theoretical physics she challenged a famous von Neumann's theorem according to which "hidden parameters that would 'complete' the quantum mechanical formalism, making it intelligible, are impossible" (p. 313). As it happened to so many talented researchers who lived beyond the Iron Curtain (this time in Romania) her access to information and direct contact with other seekers from other countries has been almost completely repressed. However, she succeeded to send, through informal networking, her draft, which she thought to be "an invalidation of von Neumann's proof", to Louis the Broglie who had a similar idea on the same theorem and the intellectual generosity to invite her to work with him, thus making in 1962 one of those small but highly significant holes in the Iron Curtain for the sake of scientific knowledge (pp. 312-315). Some 
common representations regarding the learning of abstract sciences consider that this is just a matter of intelligence, which, as a matter of fact are multiple intelligences: mathematical, linguistic, and other types of the multiple intelligences, identified by Gardner's innovative model. However, there is also the vital role of personal interaction, of scientific apprenticeship. Yuri Mannin, educated at Moscow University, with landmark contributions in mathematical physics and information, makes this extremely clear recalling the time when he struggled with specific area of "Diophantine sets": "I could easily understand what Diophantine sets were, but enumerable ones required some study. Turning to books and articles on logic, I met again what was already a familiar problem: I could not achieve understanding by just reading, other people's texts did not tell me what I felt I needed to know" (p. 279). In tune with Mannin's perspective Mugur-Schachter expresses the challenges posed to her understanding while moving from Newtonian mechanics, for instance, to quantum mechanics and says "I simply did not grasp how mathematical formalism manage to carry definite meanings" (p. 313).

The universal human need to belong (McClelland; Deci \& Ryan; Leary \& Baumeister) has a specific expression in the case of seekers: a creative mind searches to be in close personal contact with other creative minds and to belong to networks that include other creative minds. This need is hard to be satisfied in the absence of freedom as noted above. A similar experience has been lived by Grzegorz Rozenberg, a scientist formed in communist Poland who emigrated to the Netherlands, who expressed his irritation to the bookish understanding of what means "to live in a totalitarian system" (p. 336). Reading about, studying it (which is necessary) cannot fully and meaningful replace the lived experience. His experience determined him to help his Polish colleagues in many ways, inclusively by sending articles, books and keeping them connected with the free scientific community. Rozenberg is recognized for his crucial contributions in areas such as natural computing, formal language and graph transformations. Rozenberg's conception on "natural computing" transgresses in an integrative mode many disciplinary borders: "I strongly believe that research into 
natural computing will eventually lead to a novel notion (concept!) of computation, as a matter of fact to a new 'science of computation' which will be developed by the interaction/co-operation of computer scientists, biologists, chemists, mathematicians, physicists" (p. 330).

One might expect that inquiry fields such as mathematics, theoretical physics or logic are safe vis-à-vis ideological interventionism. Not so if one lives within a totalitarian system. Yuri Gurevich recalls how students, future mathematicians, have been forced in former Soviet Union to discuss at the philosophical seminar the latest documents of the Central Committee of the Communist Party", and worst to cope with an incident during which two students surrounded by the other students were "arguing whether in there was state-anti-Semitism in the USSR". He spoke and spoke, and used "whatever parables and jokes occurred to me" and concludes "I remember wishing to be able speak my mind" (pp. 385-387). This seemed impossible there, in a world of "double-speak". Mugur-Schachter had to escape, as many other talented mathematicians, the oppressive environment of communist Romania (p. 312).

The ludic side has a great role within the scientist's life. For instance, homo ludens is part of Rozeneberg's identity expressed in fields that look as being far away from the scientific thinking, as magic. As a professional magician Rozenberg points out that between science and magic are inspiring similarities such as creativity, the need to question everything, the tendency to achieve astonishing things and also cultural dissimilarities - science being mainly rational while magic is emotional, and a performing art that works on things that look impossible (pp. 332-333).

Computing science does attract researchers who have a multidisciplinary formation. For, instance Ian H. Witten educated in mathematics, computer science and electrical engineering is just one example. Besides it, he is a jazz ("the really big thing in life") and symphonic music performer, which is a great source of joy, while sailing with his own yacht is an additional "harmonious passion" (Vallerand, 2003). Witten does front line research in machine learning, in programming by demonstration, this is to say "showing a computer what to do rather than instructing it 
in some programming language" (p. 134). He, as the other direct and indirect contributors to the volume, is an insider that is profoundly interested and able to look to the dynamics of computing from the perspective of the outside world, of the "common-sense knowledge" to better grasp how society deals with knowledge: "A few hundred years ago, control of society's knowledge was rested from the Church and relocated in academic institutions. Now... our monopoly is under threat: society can collaboratively create, edit, refine knowledge artifacts without even asking us" (p. 132). During these conversations it is obvious that research work is driven by a strong intrinsic motivation that helps to face many obstacles that might be considered unimaginable at this level: numerous rejections to publications and conferences. One on of his works with Tim Bell (principal author) and Mike Fellows - Computer Science Unplugged has been rejected by 27 publishers. This resilience, power to recover from rejection and failure comes again and again during the dialogues.

Resilience in science might, in some situations, be transgenerational as it happens with the development of some new ideas that regard the foundations of mathematics as Douglas Bridges points out while underscoring the contributions of Kronecke and L. E. J. Brouwer to "constructive mathematics". Brouwer considers that "mathematical objects are creations of the human mind rather than objects in an extra-mental universe" (p. 157). Bridges, who developed together with Luminiță Vîță, a constructive approach to general topology, shares his most recent ideas regarding the Morse Set Theory as a foundation for constructive mathematics and still wonders how works in constructive mathematics can be applied to other fields such as theoretical physics (pp. 165-166). Again, the researcher underscores the role of a creative attitude toward previous unsuccessful attempts in the genesis of new questions and solutions. This example is a piece of "oral history": "Incidentally, [Erret] Bishop told me that one of the things that made him enter the constructive domain was an unsuccessful attempt he made to picture certain hypersurfaces in complex $n$-space, as part of his famous work in several complex variables" (p. 164). This fragment of "oral history" for a field of inquiry 
that is essential for organizing, storing, computing, interpreting and communicating information suggests the value of such instances that belong to oral history, but as Ong mentioned, this would be "the second orality" in human history that is possible due to mathematics, electronics and computer science and can be shared as never before. It is a revolution as it has been for the development of mental tools as the transition from oral cultural to writing, and its listing potential (Goody, 2000).

The complex transformations induced by computing have many roots within the abstract works, crucial ideas of creative individuals, of course formed within nurturing intellectual and social contexts, who might be inclined more toward theory or applications but are dedicated seekers. The dialogical interviews consistently reveal that the contributors shared a love for their work, for its fun, a work that brings the joy of discovery of new ideas and of solutions. In psychological jargon this is intrinsic motivation (Deci \& Ryan, $1945 ; 2000)$ that is so powerful within the auto-telic activities carried by creative mind as Csikszentmihalyi documented, and as very numerous experimental studies proved. Pólya's (2004) conception on the motivation of problem solving underscores the importance of intrinsic motivation, being in tune with well-established theories of motivation (Csikszentmihalyi, Deci \& Ryan, for instance). In addition, it assumes not just the development of an innate curiosity but also the role of experienced based of deep personal engagement that enables one to cope with failures and success: "The open secret of real success is to throw your whole personality into your problem" (Deci \& Ryan, 1945, p. 180).

The intrinsic motivation is pointed out in many personal forms by each and every contributor this is why I will not provide pages for this. At the same time the book points out that the epistemic orientation of the contributors is structurally marked by rigor, critical thinking, relentless self-inquiry and inter-inquiry, urge for verification and rational openness. At the same time the oral and the written history, including the personal (diaries) and interpersonal documents (letters/e-mail), suggests a fertile epistemic solidarity across time, schools, cultural borders. It is well known that letters, especially within their natural stream 
(correspondence) have been used and appreciated by scientists. Some scientists, such as Leibniz, Descartes and W. James had the custom to preserve both the sent and received letters. In other cases the preservation is rather asymmetrical - letters of one side being more frequently preserved as it happens, for instance with the correspondence between L. Wittgenstein and B. Russell. The book shows that even in the area of computing science letters might offer highly significant insights into the field. Such illuminating instances are present in the volume. One of them refers to "Gödel's lost letter and $\mathrm{P}=\mathrm{NP}$ " (p. 54). Hartmanis says: "Dr. Heise left me a copy of Gödel's letter which I found very fascinating and I was impressed by Gödel's curiosity about computational complexity of theorem proving. I translated the letter into English and published a note in the EACTS Bulletin, Gödel, von Neumann and the problem of $P=N P$, I spent some time searching for a possible reply from von Neumann but could not find it nor has it been found since then. Von Neumann was not well at the time and we now have to assume that he never replied to Gödel's letter" (p. 54). This episode strongly suggests the importance of archival mining; many of such archives that contain also letters are now open via Internet. Computing science is game changer even in the areas of oral and written History.

What can do technology and computer science for the advancement of mathematical research? Jon Borwein, who belongs to a family of mathematicians - his father, David, being the ex-President of the Canadian Mathematical Society and his brother, Peter, "a distinguished analyst and number theorist", while his grandfather from the mother side has been Hassidic rabbi in Lvov before "losing his faith" and becoming an example for "the danger of the free thinking" (p. 142) and has major contributions in pure mathematics and computational mathematics is a promoter of experimental mathematics. For him high-performance computing is crucial to the evolution of mathematics: "Much of what can be discovered without digital assistance has been. This is why I have invested so much time in advancing technology-mediated experimental mathematics” (p. 144). At the same time, stimulated by well focused questions generated during the dialogue with Calude, Borwein approached 
the painful issue of fraud in hard and abstract sciences but also in psychology and many other fields (pp. 150-155). This ethical issue proves again how much the research in these areas are impregnate by human traits, but also suggests that is highly necessary to develop intelligent self-correcting mechanism to catch, discourage and reduce fraud (in tune with Giner-Sorrola, 2012; Ioannidis, 2012; Stroebe, Postmes \& Spears, 2012).

The intellectual environment plays an important role both in the cultivation of the interest for mathematics and logics and in the self-discovery of one's potential to solve abstract problems. However, in some cases the individual choice and cognitive potential contradict the inertia of cultural reproduction and leads to major performances. This seems to be the professional journey of Rod Downey who works in classical and applied computability theory and complexity theory among other areas. He is the first one in his family, both on his maternal and paternal side "to ever go to university" while migrating from Australia to New Zeeland. Still the long journey in computing science needed a mentor. In his case, beyond the generous support received from well established scholars in the field such as Anil Nerode, who studied also philosophy with Rudolf Carnap (p. X), Downey's first mentor happened to be a headmaster. This has been Harry Seldon, in a very small school that inspired all his students "with English, poetry and mathematics" and beyond this he urged his students to have the "courage" of their "convictions" (p. 205). Assessing the value and the trajectory of some of his landmark results in complexity theory Downey observes that "it is hard to get new ideas to penetrate" (p. 213), which underscores the fact that beyond the difficulty to develop and refine a new idea the researcher has to invest huge personal resources for supporting its scientific public trajectory. Downey makes explicit that this epistemic care for the destiny of new ideas runs many times against the pressure "to conform to the current fashion in research" and to run from one deadline to the next one (p. 215). The power to delay immediate gratifications by following strong and long-term personal cognitive interests is supported by intrinsic motivation while one must be aware that she/he must pay high social (professional 
recognition) costs because on engages in bold inquiring questions that are not yet in fashion.

The evolution of computing science cannot be separated from the advancement of informatics. Jozef Gruska, who "introduced the descriptional complexity" (of grammar, automata and languages, p. 225), an after reminding us that according to Rutherford's statement (1912) "in science is only physics, the rest is stamp collecting" assesses that "informatics is currently the leading science and technology discipline with enormous impact on all other sciences, technologies, industry, economics, health and environment care, liberal art and so on..." (p. 233). This view is related to the fact that information, as Sifakis posits is "an entity distinct from matter and energy. It is a resource that can be stored, transformed, transmitted and consumed" (p. 96). Information also can be misused, stolen, distorted and falsified as it would be discussed later.

Information complexity leads to problems that are at the edge of present horizon of human knowledge. Joseph Traub set for himself the explicit goal "to move the distinction between the unknown and the unknowable from philosophy to science" (p. 124). Some four years after he visited in 1955 IBM's Watson Laboratories at Columbia and changed his professional intentions from theoretical physics to computation Traub developed the optimal iteration theory. Later on, together with Henryk Wozniakowski, he pioneered the field of "optimal algorithms and computational complexity applied to continuous scientific problems" (p. 107). His research is marked, as the research of other creative scientists, not just by a talent of problem findings, by searching new questions and solutions but also by the vision and willingness to share with all other inquiring minds novel questions refusing to keep them for the use of his inner epistemic circle. Traub recalls an episode, which can be considered as part of the oral history of science, when at the ending of a lecture at MIT he stated some "open questions". Afterwards "Marvin Minsky told me he saves his good questions for his students. I replied that there were lots more where those came from" (p. 122). It seems that scientific creativity is closely connected with an inquiring generosity that is expressed by sharing highly meaningful and inspiring 
questions. Just one additional case from the rich cases provided by the volume: while Solomon Marcus met with Paul Erdös in mid 50s the later asked: "Do you have an interesting problem?" (p. 291). The answer has been yes, and a collaborative paper has been born. This typical event has been lived by many computing scientists: Gurevich, after immigrating in Israel recalls that at the Hebrew University a young logician, Saharon Shelah asked him "Do you have an open problem?" (p. 390). The joy of searching and finding is connected with that of sharing wonders, puzzles, and tentative answers. If one takes into account that "computing is ubiquitous, it is everywhere and anywhere" and that the "world's computational power has increased by $10,000 \%$ in the last decade" as Cristian Calude says then one must seriously consider two challenges that might look like utopia but are "computing problems": "to best human intelligence and to challenge the natural death" (p. 430).

Unconscious computation is considered a necessary resource for survival. Françoise Chateline developed the theory of "qualitative computing", as a branch of mathematics that specifically looks at "how the laws of classical computation (Euler-Cauchy-Riemann-Jordan-Puiseux) are modified when mathematical computation does not take place over a commutative field" (p. 184). Chateline makes the observation that conscious computing does not seem necessary for human survival. Many individuals all over the world do quite well without this ability. But things are different for unconscious computing: "Computation that sustains life in organisms seems to take place at an unconscious level, in which measurements play an important role because the flow of information has to be delicately balanced" (p. 188). Chateline's conception leads to "a theory of information whose logic evolves naturally under the pressure of computation" (p. 193). This conception is in tune with Gödel's observation that has deep ramifications for cognitive psychology that are still waiting grasped: "what Turing disregards completely is the fact that mind in its use, is not static, but constantly developing, i.e., that we understand abstract concepts more and more as we go using them" (1972). During this dialogical interview as in many others initiated by Calude the reader has the chance to observe the epistemic 
advantage of the dialogical interviews carried out by insiders due to the nature of arguments and counter-arguments that pin-point, in a friendly and inspiring manner, areas of theoretical disagreement and wonder (pp. 190, 197). I mention this for an additional reason that points out the huge advantage of opening the dialogues about computing from within the field through insiders' participation. There are instances in which I, as a social psychologist, realized that regardless my efforts, I do not understand the formal flow of some arguments that are exchanged during some conversations. However, such instances are complemented by the clarity, including that of other highly abstract episodes, of the entire discourse of the book that opens its treasures to a wide variety of readers; its clarity is part of the transdisciplinary value of this enterprise.

Connecting efficiently and creatively theoretical and applied computer science is almost a natural way in which most of the contributors to the volume developed their projects. This is obvious in the case of Hermann Maurer who worked on the theory of data-structures and algorithms (p. 401). Pleading for the value theory he also states that theory can be "dangerous, mainly because negative results tend to scare people away from trying to solve problems whose exact solutions can be very hard, but where are very good approximate solutions" (p. 403). At the same time, he consider that without theory "we would not get anywhere in applications". This seems to be a vision that stays in contrast with a long time dominating orientation in psychology, including all the branches, as cognitive and social, that did inhibit theoretical research. Masanao Toda, trained in theoretical physics who switched to psychology after the atomic bombing of Hiroshima has been bewildered by negative attitude of the main-stream psychology in 80's toward theoretical research. He worked in artificial intelligence and developed a theory of emotions tested through his famous robot called Fungus Eater. Toda's conception in what could be called "artificial emotion" seems to be pioneering for effective computing. The cross-fertilizing dialogue between theory and application has also esthetic, including visualizing features, as suggests Reinhart Wilhelm who has important contributions in the area of "animation and visualization 
of algorithms and data structures" as well as in the area of "time-critical sub-system of the Airbus A380" (p. 421).

Scientists in the evolving field of computing science, which is not only useful for the power structures of all societies but it might be cultivated, even courted by power as shows Eric Goles, who worked on "learning algorithms to control the size of stones to feed industrial mills in Chilean copper mining" (p. 375). Goles recalls a time a time when his direct "boss" was "President Lagos" who even asked Goles "to work for him in the campaign for presidential elections" (p. 379). At the same time Goles, as Sifakis and others, has deep love for arts and literature, as it is, for instance, Borges' poetry. Precision, imagination, validity, verification, rigor as features of the scientific creativity are complemented by a deep care for the scientific language that is so much indebted to and generous with the natural languages. This care is visible in the high interest for scientific poetry, metaphors included, as Marcus reminds us, in the urge to write manifestoes as the one named "Modeling, Analysis, and Verification - The Formal Methods Manifesto 2010" co-authored by Reinhart, a manifesto that "gives and overview of haw far different formal methods, in particular the verification methods, have been take up by industry" (p. 422). Other manifesto has been worked out in 2014 in Brazil at the Global Multistakeholder Meeting on the Future of Internet Governance or by caring about the public discourse and actions relates to the ethical questions of computing science and its relationship with the governing power as suggests Moshe Y. Vardi. Manifestoes can be considered a speech/writing acts, which have the intention to produce transformation, sometimes mutations, within a wider sphere of vital importance for humans. Manifestoes can be generated in every inquiring fields. It seems to me that in computing science they have rather an heuristic character than the algorithmic one, the later marks some political manifestoes.

Ethical questions posed by computing science in our global world are present, at least implicitly, across all the conversational-interviews. In some instances the ethical issues are frontally approached. For instance, the issues of plagiarism and fraud that seem so alien from human inquiry 
that evolves by aiming toward truth, itself a moving target (Borwein, pp. 151-155) or by the restrictions imposed to scientific dynamics by "profit-oriented" competing companies (Bjørner, p. 9), by treating scientists that are forced to travel, of course legally, by the nature of their work as "non-resident alien (...) what a funny name for a non-US citizen without a green card!" (as points out from experience Gelenbe, p. 19), or by "cultural hegemony" as posits Longo: "Stressing competition of teams and individuals is a real disaster for scientific research... largely borrowed from the current cultural hegemony of the financial markets, where traders are in continual competition and they compete on a mostly empty economic/productive content" (p. 254). Ethical questions are emerging naturally from the content of theoretical and applied research. This seems to be the case with "the ontological quality of information" (Witten, p. 132) and with the field of "cryptography". Brian E. Carpenter says: "Asymmetric cryptography is computationally expensive. Efficient encryption and decryption needs some kind of shared secret that a third party find unreasonably expensive to guess, both now and reasonably far into the future" (p. 370). It seems to me that this implies the principles of reciprocity, one o the oldest principles that regulates human interactions. The same principle is implied by the issue of "authentication", which, as Carpenter clearly argues, "goes both ways", i.e., for the bank as well as for its client (p. 262). Harel's "programming behavior", which aims to cause others to do what our minds want them to do, is another area that implies ethical issues especially when the theory is intended to serve the constructions of tools such as "Play-Engine and PlayGo" (p. 41). This invites questions: What might happen if the two sides, We and Others, generate programming behavior aiming toward the other side? How this will work if each side does it secretly or openly? Can this become an inter-programming behavior creatively involving the two (or more) sides of the relationship?

The theoretical and applicative forces of computing science share, among others things, a high interest in the "most influential results" as Moshe Vardi argues. Vardi is highly recognized for his landmark contributions to the field: "I discovered the automata-theoretic perspective to program 
verification. At first this did not lead to new algorithms. As much as offered a very simple way to understand existing algorithms. (In fact, it was so simple that the paper was at first rejected when we submitted it to a conference.)" (p. 411) As a young researcher Vardi "discovered that when analyzing computational complexity of database query evaluation one has to distinguish between the contribution of the data to that complexity and the contribution of the query. These are known as 'data complexity' and 'query complexity', and have become the standard way of looking at the complexity of query evaluation" (p. 411). Theories and applications, including those at industrial scale might imply and lead to difficult ethical questions stat include managing financial resources, relationships with students, authorship, and questions about the ways and uses of research activity. Vardi opened the Research Ethic Seminar for students for exploring the moral issues including the practices to eavesdrop and censor that modified the scale and quality of the Orwellian nightmare, while almost everybody uses and enjoys the Internet, and many other goodies of the computing science. On one side, students' interest in it has been a success, on the other side it failed because "we did not have enough faculty members with an interest in the topic to make this seminar a regular course offering" (p. 413). If we consider only the Internet with its unprecedented capacity to collect, organize, store, search, process, exchange information it seems evident that its cognitive functions imply basic moral principles, as it is that of reciprocity, which can take the algorithmic form, as Carpenter suggests, of a "mutual authentication" (p. 362). While "spam, fraud, and denial-ofservice attacks have become significant social and economic problems" (Carpenter, 2006; cited at p. 361) the language, the concepts, the theory, and tools of computing science are generating answers to these issues. These answers make more and more explicit the moral nature of such approaches that attempt to keep the field free, well working and growing for the benefit of all. For instance, such a problem is "botnet", i.e., "a large set of infected computers carrying a specific item of malware (malicious software), which acts collectively as a robot, under the control of a botmaster who is a malicious individual" (Carpenter, p. 301). If we accept, 
as looks evident from the mode in which the interviewees relate to moral issues, a universal moral imperative - as Kant's Categorical Imperative - then it seems that higher degrees of interknowledge among all the decent individual and collective users (those who do not intend to harm anybody else) of Internet then the chances to generate errors and to carry unwarily viruses spread by a malicious software might be significantly reduced, and in the case they are produced might be quicker identified and eliminated.

In tune with the nature, results, goals and potential of computing science all the eminent contributors to the present volume have been engaged in creative and constructive networking works for the good of the scientific community and for the general common good. It is natural for researchers in computing science to become more interconnected and to work together with researcher that they did not ever meet face-to-face but being moved by the same motive "to understand" encountered "via the Internet. There remain co-authors I have not met" (Downey, p. 211). Such cases are quite frequent and they might lead to the increased number of authors per published study. At the same time the joy of individual work, of personal struggle with puzzles remain strong as Gelenbe, who has crucial contributions in G-networks, says: "I also wonder about papers with so many authors. I still try to keep a traditional zone of work for myself, just working by myself on certain more theoretical problems, and many of my best cited papers are single author" (p. 32). There are situations in which a few authors meet and work together during long periods of time, years interaction that does not effaces the individuation process but strengthens it. Maurer refers explicitly to the research triad "Maurer-Salomaa-Wood, with the person in the center being the central figure." He also points out the challenge of working with a person who has "the incredible talent of immediately seeing the rough solution of a very complicated problem" - as Karel Culik - who, however makes one to feel unsure "am I not clever enough to understand what he says, or it is just arm waving" while one must refine dramatically the proposed solution (p. 402).

Beyond the networking for specific research goal there is networking that explicitly aims for the development of the 
entire field to the emergence of new scientific horizons. Founding journals, research teams, academic departments and/or international research organizations is a common denominator of the interviewees. Erole Gelenbe, one of the founders of the "field of computer system and network performance analysis" created the "team that built the Queuing Network Analysis Package" (pp. 10, 21) and founded the School of Electrical Engineering and Computer Science through integrative work at University of central Florida (p. 30). Juris Hartmanis created a first-class Computer Science department at Cornell University (p. 52) and served in important committees such as Turing Award Committee, and Gödel Prize Committee, while some other scientists beyond these areas are co-founders of companies, as it is the case of I-Ligocx, cofounded by Harel in 1984, "which was acquired later on by Telelogic, and which, as of 2000 , is part of IBM" (p. 41). Grzegorz Rozenberg founded front line scientific journals and served on some 20 editorial boards (p. 328) investing, as other landmark scientists, a lot of his talent, expertise and energy in the service of the scientific community.

This orientation does exist among leading figures of many other intellectual communities. This is visible even in the area of non-funded research that is still growing even if the funded research "dwarves" it because of national economic and security goals. At the same time it seems vital that the "scientifically driven, industrially funded research" should be stronger supported to avoid decline (Vardi, p. 414). But, working toward a more efficient, creative and comprehensive connectivity that is achieved in many areas such as theoretical construction, building scientific organization and university departments, improving industrial organizations and creating new companies, has a special meaning for an inquiring area that by its own theories and applications achieved a crucial evolutionary change: the higher integration of three essential human dimensions. These three human dimensions are: (a) humans as rational, intelligent beings (Homo sapiens) that created artificial intelligence; (b) humans as tool makers, and now makers of intelligent tools (Homo faber); (c) humans as social beings, which are not just zoon politikon, or only inventors 
and users of communicational tools but are "Homo dictyous" (networking man/human, Christakis \& Fowler, 2012) through intelligent tools and within intelligent web(s). The computing science and its related inquiring areas are achieving a creative unification of Homo sapiens, Home faber, and Homo dictyous.

The imaginative, theoretical, and practical ramifications of this emerging unification remain open for questions and answers. As highly intelligent social animals, and more exactly, as networking humans the individual and collective social actors cannot escape moral questions. Due to the essential presence of Other and the interdependence with Other every human social unit (Self) encounters moral problems in the form of the individual freedom, common good, dignity, privacy, trust, honesty, altruism and of course due to various forms of violence. Computing science, as conceived, practiced, taught, and applied as it is evident form The Human Face of Computing, with all its resources and limits marks a new evolutionary stage of human understanding, technologies, applications as well as of human ways of acting and relating; all these being morally loaded. The computing science, as classical and modern mathematicians experienced before through the intrinsic features of their work, is a human activity that is highly significant for spiritual and faith questions. Dogmatic thinking and irrational authorities might become weaker as faith and reason are better connected and co-develop.

\section{References}

Boltzmann, L. (1974). Theoretical physics and philosophical problems. Dordrecht: Reidel.

Baumeister, R., Leary, M. R. (1995). The need to belong: Desire for interpersonal attachments as a fundamental human motivation. Psychological Bulletin, 117(3), 497-529.

Carpenter, B. (2006). Better, faster, more secure. Queue, 4(10), 42-48.

Christakis, N. A., Fowler, J. H. (2012). Connected: The surprising power of our social networks and how they shape our lives. How your friends' friends' friends affect everything you feel, think and do. New York: Back Bay Books. 
Csikszentmihalyi, M. (1988). Motivation and creativity: toward a synthesis of structural and energistic approaches to cognition. New Ideas in Psychology, 6(2), 159-176.

Csikszentmihalyi, M. (1991). Flow. The Psychology of Optimal Experience. New York: Harper Perennial.

Csikszentmihalyi, M. Getzels, J. V. (in press). Creativity and problem solving. In: F. H. Farley, R.W. Neperud (Eds.), The Foundations of Aesthetic, Art, and Art of Education. New York: Praeger.

Deci, E. L., Ryan, R. M. (1985). Intrinsic motivation and self-determination in human behavior. New York: Plenum.

Deci, E. L., Ryan, R. M. (2000). The "what" and "why" of goal pursuits: Human needs and the self-determination of behavior. Psychological Inquiry, 11, 227-268.

Feyerabend, P. (1979). Science in a free society. London: New Left Books.

Fuller, S. (1995). Philosophy, rhetoric, and the end of knowledge. The coming of science and technology studies. Madison: The University of Wisconsin Press.

Giner-Sorolla, R. (2012). Science or art? How aesthetic standards grease the way through the publication bottleneck but undermine science. Perspectives on Psychological Science, 7(6), 562-571.

Goody, J. (1986). The logic of writing and the organization of society. Cambridge: Cambridge University Press.

Goody, J. (1987). The interface between the written and the oral. Cambridge: Cambridge University Press.

Goody, J. (2000). The power of the written tradition. Washington: Smithsonian Institution Press.

Greenwald, A. C. (2012). There is nothing so theoretical as a good method. Perspectives on Psychological Science, 7(2), 99-108.

Holton, G. (1973). Thematic origins of scientific thought: Kepler to Einstein. Cambridge, MA: Harvard University Pres.

Holton, G. (1978). The scientific imagination. Cambridge: Cambridge University Press.

Ioannidis, J. P. (2012). Why science is not necessarily self-correcting. Perspectives on Psychological Science, 7(6), 645-654.

Knorr-Cetina, K. (1981). The manufacture of knowledge. Oxford: Pergamon Press.

Knorr-Cetina, K. (1999). Epistemic cultures. How the sciences make knowledge. Cambridge, MA: Harvard University Press.

Kuhn, T. (1962). The structure of scientific revolutions. Cambridge: MIT Press.

Latour, B. (1999). Pandora's hope. Essays on the reality of science studies. Cambridge, MA: Harvard University Press.

Latour, B., Woolgar, S. (1986). Laboratory of life: The social construction of scientific facts. Princeton: Princeton University Press. 
Lewin, K. (1951). Field theory in social science: Selected theoretical papers. New York, NY: Harper \& Row.

McClellalnd, D., C. (1961). The achieving society. Princeton, N. J.: Van Nostrand.

McClelland, D. C. (1966). The use of measures in human motivation in the study of society. In: J. W. Atkinson (Ed.), Motives in fantasy, action, and society. New York: Van Nostrand.

Merton, R. K. (1973). The sociology of science. Chicago: The University of Chicago Press.

Mitroff, I. (1974). The Subjective side of science. A Philosophical inquiry into the psychology of the Apollo Moon scientists. Elsevier: Amsterdam.

Ong, W. J. (1971). Rhetoric, Romance, and Technology. Studies in the Interaction of Expression and Culture. NY: Cornell University Press.

Ong, W. J. (1982). Orality and Literacy: The Technologizing of the Word. London: Methuen.

Pólya, G. (2004). How to solve it. A new aspect of mathematical method. Princeton: Princeton University Press.

Popper, K. (1959). The logic scientific discovery. New York: Harper and Row.

Stroebe, W., Postmes, T., \& Spears, R. (2012). Scientific misconduct and the myth of self-correction in science. Perspectives on Psychological Science, 7(6), 670-688.

Toda, M. (1982). Man, Robot, and Society. Models and Speculations. Boston: Martinus Nijhoff.

Toda, M. (1993). The urge theory of emotion and cognition. Emotion and urges, SCCS Technical Report, 93-1.

Vallerand, R. J. et al. (2003). Les passions de l'ame: on obsessive and harmonious passion. Journal of Personality and Social Psychology, 85(4), 756-767. 
